Sinüs membran

perforasyonunun trombositten zengin fibrin ile tamiri: Olgu sunumu

\section{Repair of the perforated sinus membrane with platelet rich fibrin: A case report}

\section{Yrd. Doç. Dr. Nuray Yılmaz Altıntaş}

Karadeniz Teknik Üniversitesi Diş Hekimliği Fakültesi, Ağız, Diş ve Çene Cerrahisi A.D., Trabzon

\section{Dt. Ümmügülsüm Coşkun}

Karadeniz Teknik Üniversitesi Diş Hekimliği Fakültesi, Ağız, Diş ve Çene Cerrahisi A.D., Trabzon

\section{Dt. Yavuz Tolga Korkmaz}

Karadeniz Teknik Üniversitesi Diş Hekimliği Fakültesi, Ağız, Diş ve Çene Cerrahisi A.D., Trabzon

\section{Prof. Dr. Bahar Eren Kuru}

Yeditepe Üniversitesi, Diş Hekimliği Fakültesi

Periodontoloji A.D., İstanbul

Geliş Tarihi : 25 Ocak 2016

Kabul tarihi: 31 Mart 2016

DOI: 10.5505/yeditepe.2016.09797

\section{Yazışma Adresi:}

Yrd. Doç. Dr. Nuray Yılmaz Altıntaş

Karadeniz Teknik Üniversitesi Diş Hekimliği Fakültesi, Ağız, Diş ve Çene Cerrahisi AD,

61080 Trabzon, TÜRKIYE

Tel: 04623774729 Fax: 04623253017

E-posta: dtnurayilmaz@yahoo.com

\section{ÖZET}

İkinci nesil trombosit konsantresi olarak adlandırılan trombositten zengin fibrinin (TZF), yumuşak ve sert doku iyileşmesi üzerindeki olumlu etkileri nedeniyle, diş hekimliği klinik uygulamalarında kullanımı giderek artmaktadır. Kolay elde edilmesi, uygulanmasının kolay olması ve büyüme faktörlerini barındırması TZF'nin en önemli avantajları arasındadır. Bu olgu raporunda sinüs membranı elevasyonu esnasında meydana gelen sinüs membran perforasyonunun TZF ile tamiri sunulmuştur.

Anahtar kelimeler: Maksiller sinüs ogmentasyonu, membran perforasyonu, trombositten zengin fibrin.

\section{SUMMARY}

The platelet rich fibrin (PRF) is second-generation platelet concentrate that has been widely used in clinical applications in dentistry due to its positive effects on soft and hard tissue healing. The most important advantages of PRF are the ease of preparation and manipulation and the release of growth factors. This case report proposes the use of PRF for repairing of the perforated sinus membrane during sinus membrane elevation.

Key Words: Maxillary sinus augmentation, membrane perforation, platelet rich fibrin.

\section{GíRiş}

Dental implantların kısmi veya tam dişsiz hastalarda kullanımı her geçen gün artmaktadır. Ancak maksiller posterior bölgede maksiller sinüsün pnömatizasyonunun artması, alveolar kemiğin rezorpsiyonu ve düşük kemik yoğunluğu dental implant uygulamalarında zorluklara neden olmaktadır. Bu nedenle dental implantların maksiller posterior bölgeye yerleştirilebilmeleri için sinüs tabanında ileri cerrahi teknikler ile kemik yüksekliğinin arttırıması gerekmektedir. ${ }^{1}$ Maksiller sinüs membranı elevasyonu ile maksiller posterior bölgede greft materyali kullanarak yetersiz kemik yüksekliğinin artırıması sağlanır. ${ }^{2}$ Maksiller sinüs tabanı yükseltilmesi tekniği ilk olarak Boyne tarafından tanımlanmış, Tatum tarafından geliştirilmiştir., ${ }^{2,3}$ Sinüs tabanı yükseltilmesi ile beraber dental implantların aynı anda yerleştirilmesi ile tedavide yüksek başarı oranlarına ulaşıımıştır. ${ }^{4}$ Ancak güvenilir ve yüksek 
başarı oranına sahip olmasına rağmen sinüs membranı elevasyonu işleminde komplikasyonlar yaşanabilir., 6 Sinüs membranı elevasyonu esnasında en sık karşılaşılan komplikasyon, \%10-55 oranıyla, sinüs membranının iatrojenik perforasyonudur. ${ }^{7}$ Membran perforasyonunda membran kalınlığı ve kompleks sinüs morfolojisi önemli faktörlerdendir. Ayrıca, hekimin yanlış manipülasyonu, sinüs patolojisi, daha önceden sinüse yapılmış bir müdahale ve greft materyalinin gereğinden fazla yerleştirilmesi sinüs perforasyonunun diğer nedenlerindendir. ${ }^{4}$ Sinüs membranının bütünlüğü; greft materyalinin kontaminasyonu ve/veya sinüs boşluğuna migrasyonunun engellenmesi ve implant başarısı açısından önemlidir. ${ }^{4}$ Maksiller sinüs ogmentasyonu esnasında oluşabilecek perforasyonların tamirinde, perforasyonların lokalizasyon ve büyüklüğüne göre farklı tedavi yöntemleri önerilmiştir. Rezorbe olabilen kollajen membranlar, fibrin yapıştırıcılar, sütur ve bukkal yağ grefti uygulamaları membran tamirinde önerilen yöntemlerdendir. ${ }^{8-10}$

Trombositten zengin fibrin (TZF) ilk defa Choukroun ve ark. tarafından geliştirilen; yara iyileşmesi ile bağışıklıkta görev alan ve kana ait tüm bileşenleri içeren bir trombosit konsantrasyonudur.11,12 Üç pro-enflamatuar sitokinin (interlökin-1 $\beta$, interlökin-6, tümör nekroz faktör-a) ve anti-enflamatuar sitokinin (interlökin-4) TZF'den salındığı bildirilmiştir. ${ }^{13}$ Ayrıca vasküler endotelyal büyüme faktörü ve trombosit kaynaklı büyüme faktörü gibi büyüme faktörlerinin 7 gün boyunca yavaş olarak salındığı tespit edilmiştir. Bu sayede yara iyileşmesinde, anjiogenezde önemli rol oynadığı gösterilmiştir. ${ }^{14}$ Son yıllarda, yara iyileşmesi ve yeni kemik yapımı üzerindeki pozitif etkisi nedeniyle TZF'nin bir çok alanda kullanımı artmaktadır.15

$\mathrm{Bu}$ vaka raporunda maksiller sinüs membranı elevasyonu esnasında meydana gelen membran perforasyonunun TZF kullanılarak tamiri anlatılmaktadır.

\section{OLGU}

56 yaşındaki bayan hasta, üst ve alt çenedeki kısmi diş eksiklikleri sonucu oluşan fonksiyon ve estetik kayıpları nedeniyle Karadeniz Teknik Üniversitesi Diş Hekimliği Fakülte- si, Protetik Diş Tedavisi Anabilim Dalı Anabilim Dalı'na başvurdu ve Ağız Diş Çene Cerrahisi Anabilim Dalı'na konsülte edildi. Alınan anamnezde hastanın herhangi bir sistemik rahatsızlığının olmadığı ve sigara kullanmadığı öğrenildi. Yapılan klinik muayenede ve radyografik değerlendirmeler sonucunda hastanın dental implant destekli sabit restorasyon ile tedavi edilmesine karar verildi. Radyografik muayenede yapılan ölçümler sonucunda sağ maksiller posterior bölgede kemik yüksekliğinde ileri düzeyde yetersizlik tespit edildi (Resim 1). Bu nedenle lateral sinüs lifting tekniği ile kemik yüksekliğinin ilgili bölgede arttırımasına karar verildi.

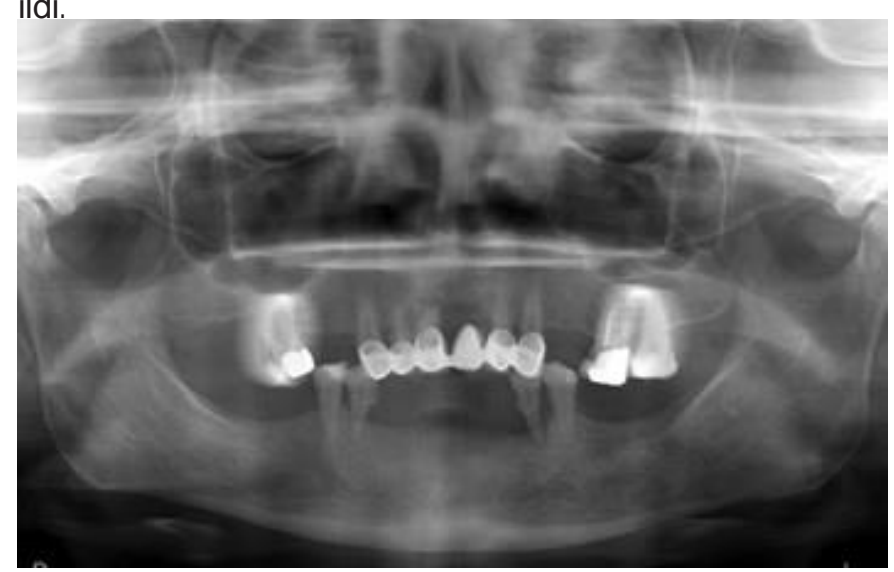

Resim 1: Pnömatize olmuş maksiller sinüsün radyografik görüntüsü

Lokal anestezi altında kret tepesinden yapılan insizyon ile rahatlatıcı vertikal insizyonlar yapıldı. Mukoperisotal flap superior yönde kaldırıldı ve maksillanın lateral duvarına ulaşıldı. Kemik penceresi irrigasyon altında rond frez kullanılarak hazırlandı. Sinüs membranı sinüs elevatörleri yardımıyla, mezial, distal ve inferior sınırlarından başlanarak eleve edildi. Her ne kadar elevasyon esnasında dikkatli olunsa da, sinüs membranında perforasyon izlendi (Resim 2). Perforasyon al-

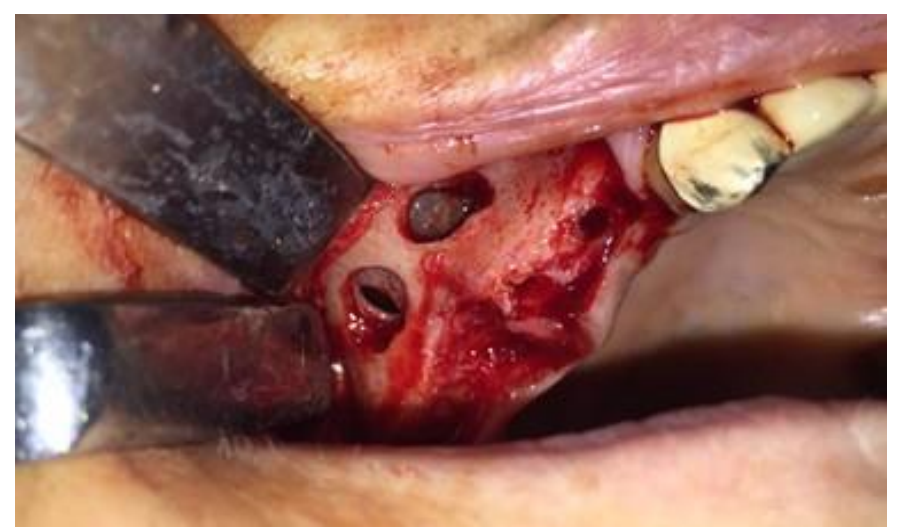


Resim 2: Sinüs membranı elevasyonu esnasında meydana gelen perforasyon

Bu nedenle hastadan operasyon anında venöz kan alındı ve 10 cc'lik antikoagülan içermeyen tüplere aktarıldı. 3000 rpm'de 10 dakika boyunca santrifüj edilerek TZF membranlar elde edildi. Perfore olan sinüs membranı önce 5/0 vicryl sütur ile dikkatlice süture edildi (Resim 3). Perforasyon alanının üzerine TZF yerleştirildi (Resim 4). Dental implant
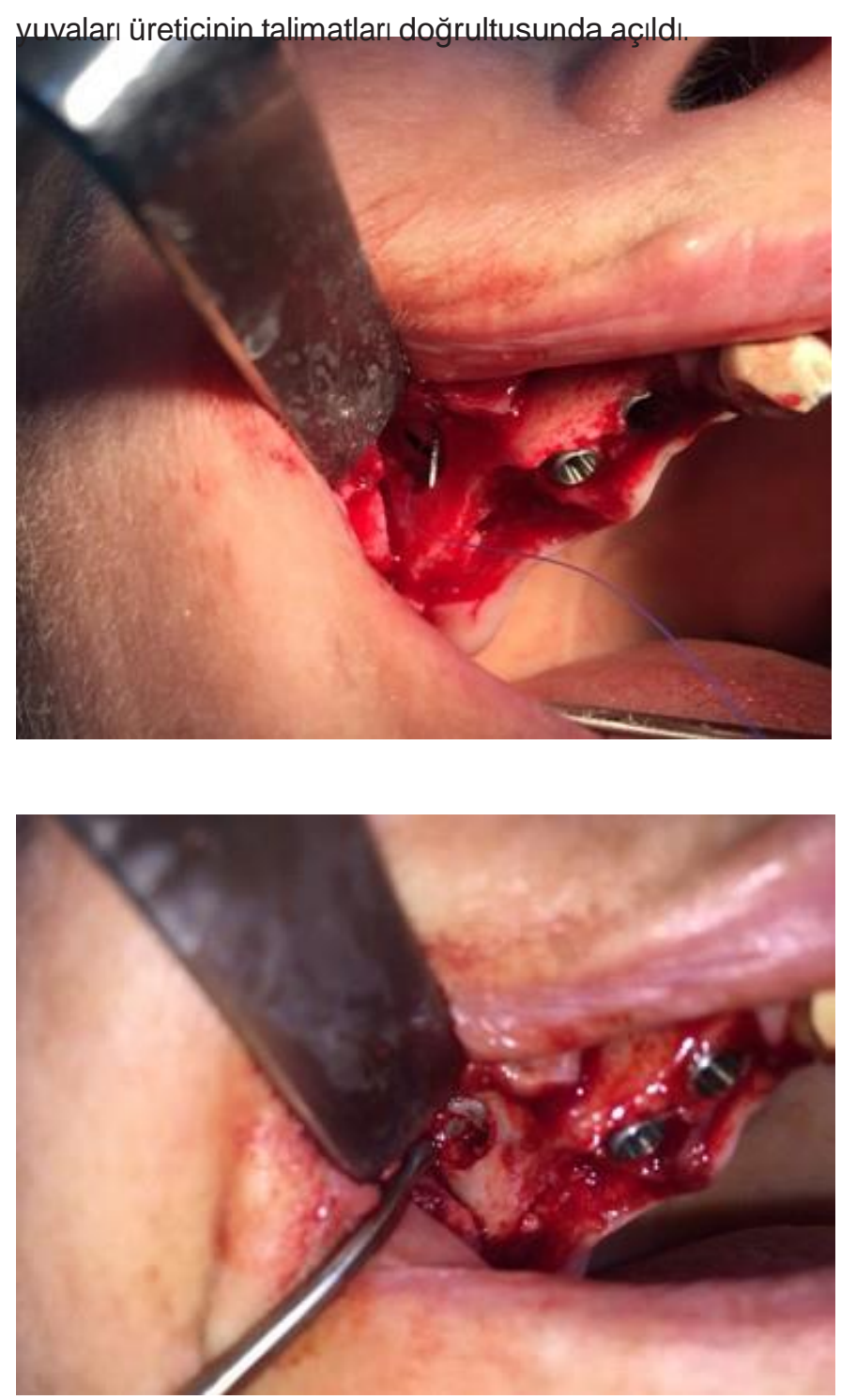

Resim 4: Perforasyon alanına TZF membranın yerleştirilmesi

Sinüs membranı eleve edilerek oluşturulan boşluk allojenik kortikokansellöz kemik greft materyali (Maxxeus Dental, USA) ile dolduruldu ve dental implantlar (Implance, Türkiye) hazırlanan yuvalara yerleştirildi. Greftin kalan kısmi ise kemik penceresinin açıldığı bölgeden implantların çevresine uygulandı. Maksillanın lateral duvarında hazırlanan kemik penceresi elde edilen TZF ile kapatıldı. Kanama kontrolü yapıldı ve flep $3 / 0$ ipek sütur ile primer olarak kapatıldı. Cer- rahi işlemden sonra antibiyotik (amoksisilin+klavulanik asit), analjezik-antienflamatuar (deksketoprofen), ağız gargarasından (benzidamin HCL+ klorhesidin glukonat) oluşan standart bir reçete önerildi.

İyileşme dönemi sorunsuz olan hasta periyodik kontrollere çağrıldı. Yapılan radyolojik değerlendirmelerde ogmentasyon yapılan sahada yeni kemik oluşumu izlendi ve dental implantların osseointegrasyonunun sağlandığı

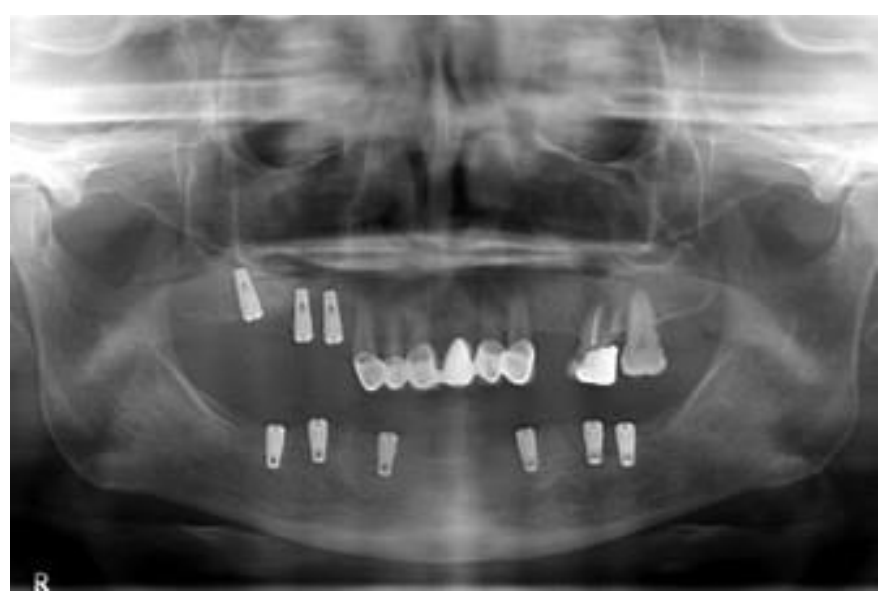

Resim 5: Postoperatif 6. ay panoramik radyografi görüntüsü

\section{TARTIŞMA}

Maksiller sinüs membranı elevasyonunda en sık görülen komplikasyon sinüs membranının perforasyonudur. Membran perforasyonun meydana gelmesiyle, perforasyonun tamir edilmemesi veya tamirinin tam yapılamadığı durumlarda; sinüs boşluğundan greft materyaline bir pencere açılmış olur. Bunun sonucunda enfeksiyon, kronik sinüzit, greft ve implant kaybı gözlenebilir., ${ }^{7,16}$ Literatürde oluşan sinüs perforasyonların tamirinde kullanılan bir çok teknik mevcuttur. Rezorbe olabilen membran, otojen kemik grefti, sütur ve fibrin yapıştırıcı uygulamaları bunlardan en yaygın olarak kullanılanlarıdır. ${ }^{17} \mathrm{Bu}$ tekniklerden farklı olarak Hassani ve ark.10 birçok maksiller defektte kullanılan pediküllü bukkal yağ dokusunu perforasyon tamiri için kullanmış ve 4 ay sonra dental implant yerleştirmek için yeterli kemik yüksekliği elde ettiklerini rapor etmişlerdir. Baykul ve Fındık ${ }^{18}$, antral pseudokist mevcut olan hastada meydana gelen membran perforasyonunu sadece TZF ile yerleştirerek tamir etmişler ve 6 ay sonra dental implantları yerleştirebilmişlerdir. Benzer şekilde bu olgu sunumunda, maksiller sinüs ogmentasyonu 
esnasında meydana gelen perforasyon alanı önce süture edildi ve daha sonra üzerine TZF yerleştirildi. Rezidüel kemik miktarı tek aşamalı sinüs ogmentasyonu için yeterli olduğundan, dental implantlar hazırlanan yuvalara aynı seansta yerleştirildi. 6 aylık takip sonrasında, dental implantların osseointegrasyonunun sağlandığı ve maksiller sinüste yeni kemik oluşumu tespit edildi.

TZF' nin elde edilişinin kolay olması, büyüme faktörleri ve savunma hücreleri açısından zengin olması, elde edilirken kimyasal bir ajana intiyaç duyulmaması gibi avantajlara sahiptir.12 Yara iyileşmesinde önemli bir rol oynayan TZF'de bulunan maddeler yumuşak doku iyileşme ve olgunlaşmanın üç fenomeni olan anjiogenesis, immunite ve epitelyal kapanmayı destekler. ${ }^{19}$ Mikrovaskülarizasyon gelişimini destekleyen ve epitelyal hücre göçünü yönlendiren doğal bir biyomateryal olan TZF açık yaraları korumak ve iyileştirmeyi hızlandırmak için kullanılmaktadır.14,20

TZF membran fibrinin ağ yapısına benzer yapıya sahiptir ve daha etkili hücre göçüne ve proliferizasyonuna neden olur. Bu nedenle de sikatrizasyonda etkilidir. Yapılan çalışmalarda TZF'nin insan osteoblast hücrelerinin, periodontal ligament fibroblastlarının, gingival fibroblastların ve pulpa fibroblastlarının proliferizasyonunu artırttığı bildirilmiştir. ${ }^{21-23}$ Gassling ve ark. yaptıkları çalışmada in vitro olarak TZF ve kollajen membran karşılaştırılmış, TZF'nin kollajen membrana göre hücre proliferasyonu için daha iyi bir iskelet oluşturduğu görülmüştür. Çalışmacılar TZF'nin kollajen membrana üstünlüğünü trombositlerden salınan büyüme faktörlerinin varlığıyla ilişkilendirmişlerdir. ${ }^{24}$ TZF'nin yara iyileşmesi ve epitelizasyon sürecindeki özelliklerinden yararlanmak amacıyla, bu olgu sunumunda meydana gelen perforasyon TZF ile başarılı bir şekilde kapatıldı.

\section{SONUÇ}

Uygulama kolaylığına sahip olması, doğal ve hızlı elde edilen bir materyal olması ve ucuz olması gibi avantajlara sahip TZF, sinüs membran kapama yöntemlerinde kullanılan kollajen membran ve fibrin yapıştırıcılar gibi tedavi seçeneklerine alternatif olabilir. Ancak sinüs membran perforasyonunun tamirinde TZF uygulamasının etkinliğinin belirlenebilmesi için randomize kontrollü klinik çalışmalara intiyaç vardır.

\section{KAYNAKLAR}

1. Riben C, Thor A. The Maxillary Sinus Membrane Elevation Procedure: Augmentation of Bone around Dental Implants without Grafts-A Review of a Surgical Technique. Int J Dent 2012; 2012: 105483.

2. Boyne PJ, James RA. Grafting of the maxillary sinus floor with autogenous marrow and bone. J Oral Surg 1980;38:613-616.

3. Tatum H, Jr. Maxillary and sinus implant reconstructions. Dental Clin North America 1986; 30: 207-229.

4. Nolan PJ, Freeman K, Kraut RA. Correlation between Schneiderian membrane perforation and sinus lift graft outcome: a retrospective evaluation of 359 augmented sinus. J Oral Maxillofac Surg 2014; 72: 47-52.

5. Boffano P, Forouzanfar T. Current concepts on complications associated with sinus augmentation procedures. J Craniofac Surg 2014; 25: e210-212.

6. Moreno Vazquez JC, Gonzalez de Rivera AS, Gil HS, Mifsut RS. Complication rate in 200 consecutive sinus lift procedures: guidelines for prevention and treatment. J Oral Maxillofac Surg 2014;72:892-901.

7. Pikos MA. Maxillary sinus membrane repair: update on technique for large and complete perforations. Implant Dent 2008; 17: 24-31.

8. Fugazzotto P, Melnick PR, Al-Sabbagh M. Complications when augmenting the posterior maxilla. Dent Clinics North America 2015; 59: 97-130.

9. Proussaefs P, Lozada J, Kim J. Effects of sealing the perforated sinus membrane with a resorbable collagen membrane: a pilot study in humans. J Oral Implant 2003; 29: 235241.

10. Hassani A, Khojasteh A, Alikhasi M. Repair of the perforated sinus membrane with buccal fat pad during sinus aug mentation. J Oral Implant 2008; 34: 330-333.

11. Choukroun JA, Schoffler C, Vervelle A. Une opprtumnité en paroimplantologie: Le PRF. Implantodontie 2001; 42: 55- 
62.

12. Eren GA, G. . Lökosit ve Trombositten Zengin Fibrinin

Özellikleri ve Diş Hekimliğinde Kullanım Alanları. İstanbul Üniversitesi Diş Hekimliği Fakültesi Dergisi 2014; 48: 73-83.

13. Choukroun J, Diss A, Simonpieri A, et al. Platelet-rich fibrin (PRF): a second-generation platelet concentrate. Part V: histologic evaluations of PRF effects on bone allograft maturation in sinus lift. Oral Surg Oral Med Oral Pathol Oral Radiol Endod 2006; 101: 299-303.

14. Dohan DM, Choukroun J, Diss A, et al. Platelet-rich fibrin (PRF): a second-generation platelet concentrate. Part III: leucocyte activation: a new feature for platelet concentrates? Oral Surg Oral Med Oral Pathol Oral Radiol Endod 2006; 101: e51-55.

15. Soydan SS, Uckan S. Management of bisphosphonate-related osteonecrosis of the jaw with a platelet-rich fibrin membrane: technical report. Journal of oral and maxillofacial surgery : official journal of the American Association of Oral and Maxillofacial Surgeons 2014; 72: 322-326.

16. Sakkas A, Konstantinidis I, Winter K, Schramm A, Wilde F. Effect of Schneiderian membrane perforation on sinus lift graft outcome using two different donor sites: a retrospective study of 105 maxillary sinus elevation procedures. GMS Interdiscip Plast Reconstr Surg DGPW. 2016; 5

17. Choi BH, Zhu SJ, Jung JH, Lee SH, Huh JY. The use of autologous fibrin glue for closing sinus membrane perforations during sinus lifts. Oral Surg Oral Med Oral Pathol Oral Radiol Endod 2006; 101: 150-154.

18. Baykul T, Findik Y. Maxillary sinus perforation with presence of an antral pseudocyst, repaired with platelet rich fibrin. Annals of Maxillofac Surg 2014; 4: 205-207.

19. Choukroun J, Diss A, Simonpieri A, et al. Platelet-rich fibrin (PRF): a second-generation platelet concentrate. Part IV: clinical effects on tissue healing. Oral Surg Oral Med Oral Pathol Oral Radiol Endod 2006; 101: e56-60.

20. Balcı HT, H. . Trombositten Zengin Fibrin: Özellikleri ve Diş Hekimliğinde Kullanımı. GÜ Diş Hek Fak Derg 2011; 29: 183-192.
21. Simon BI, Gupta P, Tajbakhsh S. Quantitative evaluation of extraction socket healing following the use of autologous platelet-rich fibrin matrix in humans. The International journal of periodontics \& restorative dentistry 2011; 31: 285-295.

22. Chang YC, Zhao JH. Effects of platelet-rich fibrin on human periodontal ligament fibroblasts and application for periodontal infrabony defects. Aust Dent J 2011; 56: 365371.

23. Chang IC, Tsai $\mathrm{CH}$, Chang YC. Platelet-rich fibrin modulates the expression of extracellular signal-regulated protein kinase and osteoprotegerin in human osteoblasts. J Biomed Material Res Part A 2010; 95: 327-332.

24. Gassling V, Douglas T, Warnke PH, Acil Y, Wiltfang J, Becker ST. Platelet-rich fibrin membranes as scaffolds for periosteal tissue engineering. Clin Oral Implants Res 2010; 21: $543-549$ 
7tepeklinik 